\title{
About the role of physical trainers, sport science, powermeters and "big data" in professional road cycling
}

\author{
Mikel Zabala ${ }^{1} \bowtie$; Alejandro Javaloyes ${ }^{2} \&$ Manuel Mateo-March ${ }^{3}$
}

\begin{abstract}
It has been several years since the UCI (Union Cycliste Internationale) pointed out the necessity for the World Tour category teams to fulfil a new requirement. It was called the "organizational criteria". This criterion is focused on organizing all the issues in relation to cyclists' training programs and physical demands to secure that they are well managed and directed by the teams by means of their sport directors, doctors, and physical trainers. Maybe together with the Biological Passport, this has been one of the most important changes to create a safer environment far from doping culture in the modern elite professional cycling.
\end{abstract}

As we suggested in the first issue of Journal of Science and Cycling (Zabala and Atkinson, 2012), a new teamworking philosophy was really needed to empower a new culture in cycling environment, avoiding all the shades of the dark past to create new lights to make a clearer, more credible, and better context. This was also suggested recently (Zabala, 2017): "We must inspire those still affected by the worst part of the "old school" by promoting collaborative work that focuses on the athlete. Real teamwork is a key point, requiring collaborative work...". And, thanks to the UCI, first with President Cookson and now with President Lappartient, all the required steps seem to go in this direction.

The "organizational criteria" obligates the teams to include a specific number of physical trainers and a Head Coach to ensure that all the process of training plans and practical development is well performed. In this sense, teams usually include officially as a member of the team such professionals (normally in possession of Sport Sciences degree) and sometimes few retired cyclists with specific titles and expertise can be accepted (although this is an interesting debate about professional competencies and tittles, as for instance Doctors are forbidden to act as physical coaches while others with no university titles can do so).
The good thing is that real team-work is already being done in professional world tour teams and that instead of talking about "dark potions" everybody is talking about training load, recovery status, hydration, watts... or other "big" or "marginal gains" and variables to be improved. And may be more important, other lower category teams are copying this model so that physical trainers are being included in their staff to better guide those "continental", U23 or Junior cyclists.

Of course, we cannot be naïve thinking that that "old era" has totally disappeared, but for sure a new working culture has evolved. In fact, the culture of data analysis and use has appeared in cycling, so that using the big amount of data collected mainly by means of powermeters and other specific devices, some specialists can create useful information to control training loads, pacing strategies, recovery status etc. This is why some sponsors have been attracted by this sport as cycling can generate a very interesting amount of information that can be used to develop a more professionalized sport. For some people this means evolution and improvement, for other more traditionalists this means a more controlled and many times boring sport that does not allow cyclists' creativity by means of their feeling and not the use of specific performance feedback. So, at this point we find another new debate: should powermeters be forbidden during racing in professional cycling? Well, we have not a correct answer now. Anyway, we do believe that technology is out there, even recreational cyclists use powermeters, and now we are creating a new cycling culture based on scientific knowledge and teamworking. Also, spectators are aware and familiarized with this kind of data and they want to know more and more about professional cyclists' performance, thousands of them want to relate their data to those that admire. This is why instead of not allowing this kind of devices during races, the marketing around the use of this data should be empowered to make cycling more 
credible, more scientific and modern and closer to the spectator.

We must remind that the first cycling powermeter was built in 1985, and in the latest 90s and the first half of 2000s almost every professional cyclist was "carrying" a powermeter on the bike, with no idea of how to use this kind of data in their training plans or races. Yes, most of those doctors (there were no physical trainers) were not interested in training loads or training plans, and less in watts. So, we think that a new cycling culture means to respect professional roles, to make a real team-work environment, and also not to neglect the good use of technology (that is so popular and useful), so we can continue making cycling a really renewed sport. Let's focus on ethics, professionalism and we will ensure that the dark past of cycling is just a part of our history (that must be known not to be repeated) and that the new cycling era here to sustain this sport healthy showing its best image and projection all over the world.

\section{Conflict of interest}

None

\section{Keywords}

Powermeters; big data; doping; road cycling; professional cycling.

\section{References}

1. Zabala, M. and Atkinson, G. (2012). Looking for the "athlete 2.0": a collaborative challenge. Journal of Science and Cycling, 1: 1-2.

2. Zabala, M. (2017). Doping's dark past and a new cycling era. In Cycling Science, Human kinetics, Champaign (Illinois), 18:220-232

\footnotetext{
1 Faculty of Sport Science, University of Granada, Spain ${ }^{2}$ Department of Sport Science, Sports Research Centre, Miguel Hernandez University, Elche, Spain.

${ }^{3}$ Spanish Cycling Federation
}

$\bigotimes$ Contact email: mikelz@ugr.es 